\title{
Enhanced Etching, Surface Damage Recovery, and Submicron Patterning of Hybrid Perovskites using a Chemically Gas-Assisted Focused-lon Beam for Subwavelength Grating Photonic Applications
}

\author{
Mohd S. Alias, ${ }^{* \dagger}{ }^{\dagger}$ Yang Yang, ${ }^{\ddagger}$ Tien $\mathrm{K} . \mathrm{Ng}{ }^{\dagger}$ Ibrahim Dursun, ${ }^{\S}$ Dong Shi, ${ }^{\S}, \#$ Makhsud I. Saidaminov, ${ }^{\S}$ \\ Davide Priante, ${ }^{\dagger}$ Osman M. Bakr, ${ }^{\S}$ and Boon S. Ooi ${ }^{*}{ }^{\dagger}$ \\ ${ }^{\dagger}$ Photonics Laboratory, Computer, Electrical, and Mathematical Sciences and Engineering (CEMSE); ${ }^{\dagger}$ Imaging \& Characterization \\ Core Lab; and ${ }^{\S}$ Solar \& Photovoltaics Engineering Research Center (SPERC), Physical Sciences and Engineering (PSE), King \\ Abdullah University of Science \& Technology (KAUST), Thuwal 23955-6900, Saudi Arabia
}

Supporting Information

ABSTRACT: The high optical gain and absorption of organic-inorganic hybrid perovskites have attracted attention for photonic device applications. However, owing to the sensitivity of organic moieties to solvents and temperature, device processing is challenging, particularly for patterning. Here, we report the direct patterning of perovskites using chemically gas-assisted focused-ion beam (GAFIB) etching with $\mathrm{XeF}_{2}$ and $\mathrm{I}_{2}$ precursors. We demonstrate etching enhancement in addition to controllability and marginal surface damage compared to focused-ion beam (FIB) etching without precursors. Utilizing the GAFIB etching, we fabricated a uniform and periodic submicron perovskite subwavelength grating (SWG) absorber with broadband absorption and nanoscale precision. Our results demonstrate the use of FIB as a submicron patterning tool and a means of providing surface treatment (after FIB patterning to minimize optical loss) for perovskite photonic nanostructures. The SWG absorber can be patterned on perovskite solar cells to enhance the device efficiency through increasing light trapping and

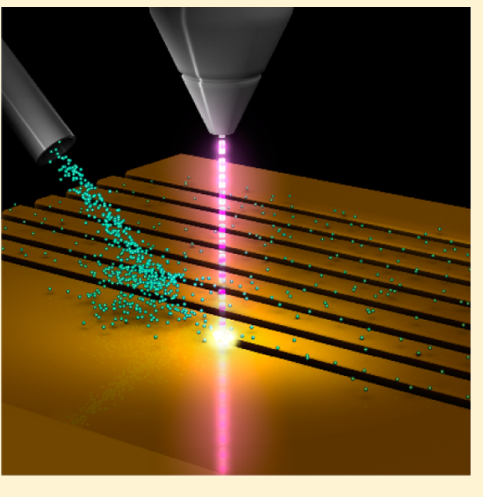
absorption.

$\mathrm{R}$ ecently, organic-inorganic hybrid perovskites especially $\mathrm{MAPbX}_{3}$ (where $\mathrm{MA}$ is $\mathrm{CH}_{3} \mathrm{NH}_{3}$ and $\mathrm{X}$ is single element or mixture of $\mathrm{Cl}, \mathrm{Br}$, or $\mathrm{I}$ ) have attracted great interest for applications in photonic devices, such as solar cells, lightemitting diodes, lasers, photodetectors, and phototransistors. $^{1-5}$ To realize significant device advancement, several device fabrication challenges must be overcome, particularly in the area of patterning. For photonic devices, besides fabricating metal contacts, patterning is required to control light-matter interaction, for example, patterning periodic structures such as gratings for diffraction and mesa structures for waveguiding. Due to the sensitivity of the organic moiety in perovskites, established patterning techniques, such as photolithography and electron beam lithography (particularly for nanoscale features), are not suited for the hybrid material. These techniques are hindered by concerns over material deterioration upon exposure to process solvents (adhesion-promoters, resists, strippers, developers, and wet etchants) and baking temperatures for both lithography techniques.

To date, most perovskite photonic devices have used shadow mask patterning. ${ }^{6-8}$ Although a shadow mask is simpler for the initial device development and is flexible for any material, the resolution is typically poor (greater than tens of microns). More advanced patterning techniques in the form of colloidal monolayer lithography $(\mathrm{CML})^{9}$ and seeded growth process (SGP $)^{10}$ have been reported recently for perovskite solar cells and photodetector/phototransistor, respectively. However, in both of these techniques, the patterned perovskites are in random orientations and the patterns are on the microscale $(1-30 \mu \mathrm{m})$. For photonic devices, it is essential to pattern perovskites with uniform orientation (periodicity) to ensure homogeneous light-matter interaction. Moreover, the photonic structure requires periodic dimensions close to the wavelength of light (thus demanding submicron patterning for devices operating in the visible spectrum). In addition, the CML and SGP techniques are complicated and exhibit poor patterning tolerance because the patterning is actually performed on the substrate (as the growth template) for subsequent perovskite coating or deposition. As a thicker perovskite is coated or deposited onto the patterned substrate, the formed structure will be patterned coarsely. Recently, we have reported direct patterning on perovskites using focusedion beam (FIB) etching. ${ }^{11}$ We performed a systematic patterning study that produced perovskite subwavelength grating (SWG) reflector with submicron periodic patterning of high uniformity. Although FIB etching throughput is low because the milling is based on a focused ion, projection focused ion multibeam ${ }^{12-14}$ is now being developed to overcome this limitation. Also, in using energetic Ga ions in

Received: November 16, 2015

Accepted: December 19, 2015 
the FIB, surface damage from ion implantation and surface amorphization is unavoidable. ${ }^{15}$ This surface damage contributes to optical losses for photonic devices patterned via FIB. ${ }^{16,17}$ Despite all these drawbacks, FIB offers a straightforward route for patterning on perovskite due to incompatibility of photo- or electron beam-lithography as described earlier.

Here, we demonstrate a direct patterning on a perovskite $\left(\mathrm{CH}_{3} \mathrm{NH}_{3} \mathrm{PbBr}_{3}\right)$ using chemically gas-assisted focused-ion beam (GAFIB) etching. In this technique, halide gaseous precursors of $\mathrm{XeF}_{2}$ and $\mathrm{I}_{2}$ were injected using gas nozzles onto the perovskites surface. The interaction between the injected gas and material surface form volatile etch-products enhancing the physical etching of GAFIB. Depending on the substrate material (for example $\mathrm{Si}, \mathrm{GaAs}, \mathrm{GaN}$, InP, $\mathrm{SiO}_{2}, \mathrm{Cu}, \mathrm{Ti}$, or PMMA), various chemicals precursors such as $\mathrm{Cl}_{2}, \mathrm{I}_{2}, \mathrm{Br}_{2}, \mathrm{XeF}_{2}$, $\mathrm{H}_{2} \mathrm{O}, \mathrm{O}_{2}$, or $\mathrm{NH}_{3}$ can be selected for the GAFIB etching. ${ }^{18}$ Because perovskites are a hybrid organic-inorganic material, we specifically selected $\mathrm{XeF}_{2}$ and $\mathrm{I}_{2}$ as the chemical precursors for our GAFIB etching. These precursors have been previously shown to enhance etching (2-5 magnitudes) for PMMA (which is an organic material). ${ }^{19}$ With the assistance of chemical reaction, the GAFIB etching can enhance etching, reduce surface damage, decrease the redeposition effect, and etch selectively. ${ }^{20}$ Utilizing the GAFIB etching, we demonstrated (1) etching enhancement and controllability, (2) significant surface damage recovery, and (3) fabrication of uniform and periodic submicron SWG absorber with nanoscale precision on the perovskite. Reducing perovskite surface damage is vital to ensure minimal optical loss for photonic devices, whereas the SWG absorber can enhance light trapping and absorption in perovskite solar cells to increase power conversion efficiency (PCE).

To study the etching enhancement, we performed FIB etching (details in the experimental section in the Supporting Information) on the perovskite with various ion doses. The ion dose is defined as the number of coulombs per micron squared that strike the substrate (which is ion beam current multiplied by milling time and divided by area of patterning). The scanning electron microscopy (SEM) images are shown in Figure $\mathrm{S} 1$. We repeated the same patterning for the GAFIB etching by injecting the $\mathrm{XeF}_{2}$ and $\mathrm{I}_{2}$ gases on the perovskite surface during the ions milling. The high-energy Ga ions dissociate these halide gases into $\mathrm{F}$ radicals (for $\mathrm{XeF}_{2}$ ) and $\mathrm{I}$ radicals (for $\mathrm{I}_{2}$ ). Figure la shows the volume of perovskite material being etched as a function of ion charge (ion current multiplied by patterning time). The slope of the linear fit indicates the sputtering yield (defined as the ratio of volume etched to product of ion beam current and etching time) of $0.01979,0.00985$, and $0.02751 \mu \mathrm{m}^{3} / \mathrm{pC}$ for patterning with ions, $\mathrm{XeF}_{2}$, and $\mathrm{I}_{2}$, respectively. Compared to perovskite etching with ions, the GAFIB etching etched the perovskite material at different sputtering yields, as shown in Figure $1 \mathrm{~b}$. However, at higher ion doses $\left(>25 \mathrm{pC} / \mu \mathrm{m}^{2}\right)$, all GAFIB and FIB etchings exhibit almost constant sputtering yields due to the redeposition effect. Figure 1c exhibits the enhancement factor (GAFIB sputtering yield to FIB sputtering yield ratio) for each of the halide gases. In the case of $\mathrm{I}_{2}$, the enhancement was 1.62 times, depending on the ion dose. For the case of $\mathrm{XeF}_{2}$, no enhancement of etching was observed (depending on the ion dose, 0.6 to 0.97 times below the FIB etching). These results suggest that I radicals are more reactive (in creating volatile etch-products) with perovskites than F radicals. However, both halides gases demonstrated decrement of the etching enhance- (a)
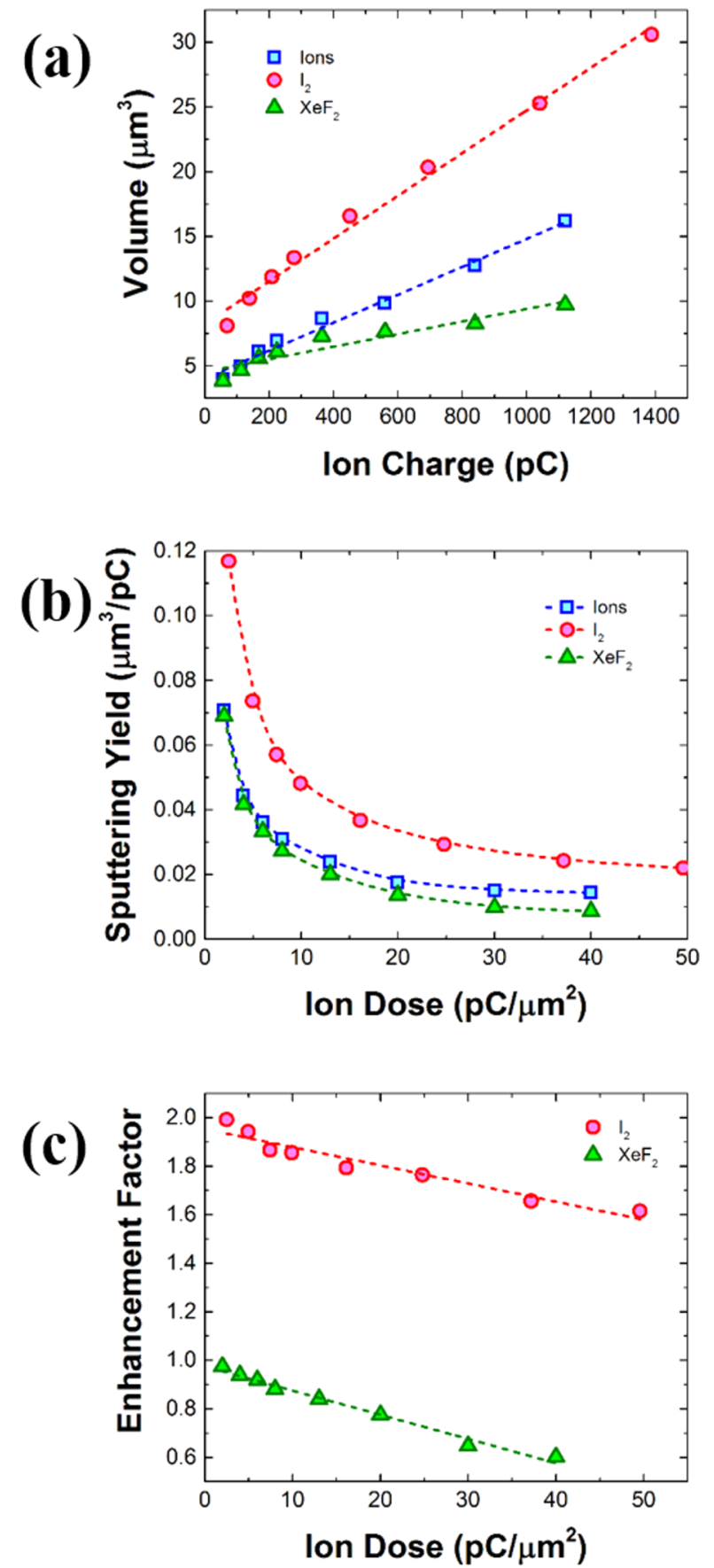

Figure 1. Comparison of FIB and GAFIB etchings for etching the perovskite, specifically showing the (a) volume of perovskite material being etched as a function of ion charge, (b) sputtering yield as a function of ion dose, and (c) enhancement factor of GAFIB etching as a function of ion dose. The dotted lines in panels a and $\mathrm{c}$ are linear fits, whereas the dotted lines in panel $\mathrm{b}$ show the general trend.

ment at higher patterning doses. At these doses, more ions impinged upon the material surface, leading to exhaustion of gaseous reactants, and the process is dominated by ion sputtering as precursor transport by adsorption and surface diffusion is apparently limited in these regimes. In addition, the redeposition effect becomes significant as the ion dose increases. $^{11}$

To investigate the variation of etching enhancement factor, as shown in Figure 2, we performed the FIB and GAFIB 


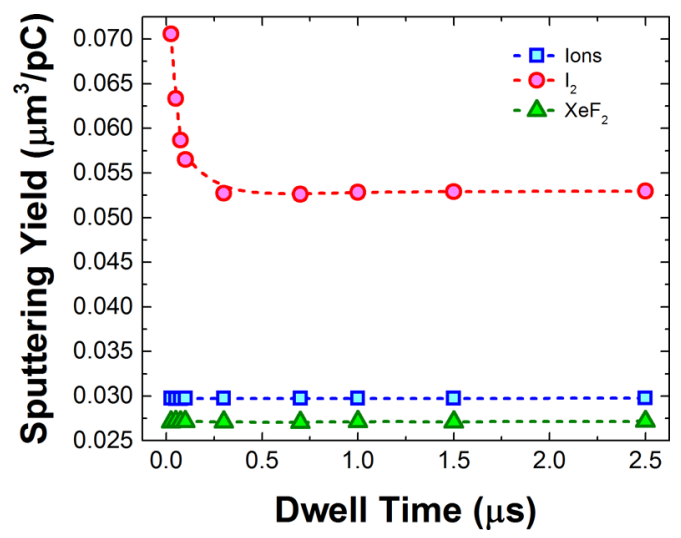

Figure 2. Comparison of FIB and GAFIB etching processes on the perovskite showing the sputtering yield as a function of dwell time to demonstrate chemically assisted (volatile) etching versus physical sputtering (nonvolatile) etching.

etching processes over a range of short to longer dwell time (defined as the time for which each pattern pixel is exposed to the ion beam). As expected, a constant sputtering yield was obtained by FIB etching for the entire range of dwell time because the etching using ions is due to only physical sputtering. For the GAFIB etching, a higher sputtering yield was expected at the short dwell time due to the chemically assisted process. Because the reaction products are supposedly volatile and thus easily pumped away, any redeposition should be reduced, resulting in deeper etching. Figure 2 shows that a high sputtering yield ( $>2$ factor) was obtained for $\mathrm{I}_{2}$ within a short dwell time $(<0.1 \mu \mathrm{s})$, implying that the etching was chemically assisted during this period. For a longer dwell time $(>0.3 \mu \mathrm{s})$, the gas reaction is depleted, and the perovskite material is now removed purely by physical sputtering (nonchemical). The initial high sputtering yield suggested that I radicals reacted volatilely with the perovskite. Although the sputtering yield became constant at longer dwell time, the yield is still higher because of the initial deeper etching. It has been reported that reaction rate is rapid for the synthesis of $\mathrm{CH}_{3} \mathrm{NH}_{3} \mathrm{PbI}_{3}$ compared to synthesis of $\mathrm{CH}_{3} \mathrm{NH}_{3} \mathrm{PbCl}_{3}{ }^{21}$ In our case, we assume that the volatile etch-products of $\mathrm{PbI}_{2}$ and $\mathrm{CH}_{3} \mathrm{NH}_{3} \mathrm{I}$ are formed easily on the perovskite surface with the introduction of $\mathrm{I}$ radicals, thus increasing the etching chemically. As for the GAFIB etching using $\mathrm{XeF}_{2}$, no etching enhancement was observed (as shown in Figure 1c), because the etch-product is nonvolatile, which results in shallow etching depth. Figure 2 shows that a constant trend was obtained, similar to the case of ions (FIB etching) for the whole range of dwell time, indicating that the perovskite material was sputtered only physically. We attributed the lack of volatility to the formation of $\mathrm{CF}$ polymerization islands on the perovskite surface. The CF polymerization is easily formed on C-enriched material, such as organic ${ }^{22}$ and polymer ${ }^{23}$ materials, during fluorination, which can hinder continuous etching and flushing of etch products. The results of electron dispersive X-ray (EDX) analysis shown in Figure S2 shows the CF presence for the $\mathrm{XeF}_{2}$-assisted etching. SEM imaging (Figure S3a) shows the $\mathrm{CF}$ islands formation on the perovskite surface etched with $\mathrm{XeF}_{2}$. Regarding $\mathrm{FIB}$ and $\mathrm{I}_{2}$ GAFIB etching processes, a homogeneous surface is obtained, as shown in panels $b$ and $c$ of Figure S3, respectively. Although we stated earlier that $I_{2}$ and $\mathrm{XeF}_{2}$ enhanced etching for PMMA, ${ }^{19}$ we observed etching enhancement for only $\mathrm{I}_{2}$-assisted etching in the case of the perovskite. In addition to the volatile etch-products for $\mathrm{I}_{2}$ assisted etching and CF polymerization factors, as discussed earlier, $\mathrm{Pb}$ alloy can be etched only with $\mathrm{I}_{2}$ and not $\mathrm{XeF}_{2}{ }^{24}$

To study the surface damage, we analyzed the perovskite surface with photoluminescence (PL) and Raman measurements (all spectra normalized to the pristine sample). Figure $3 \mathrm{a}$
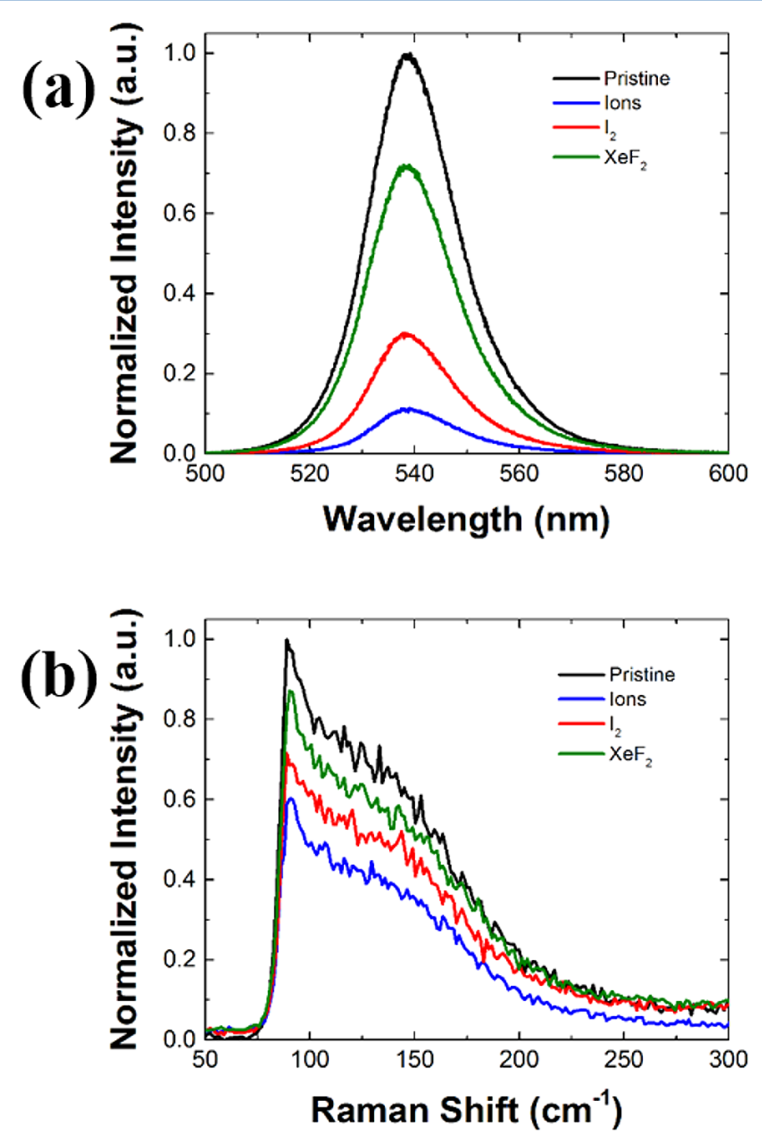

Figure 3. Signal recovery comparison for perovskite surfaces etched via FIB and GAFIB etching processes using optical characterizations of (a) PL emission and (b) Raman scattering. All spectra are normalized to a pristine perovskite surface for comparison.

shows the PL spectra for perovskite surfaces etched via FIB and GAFIB etching processes (details in the experimental section of the Supporting Information). With FIB etching, the perovskite surface was severely damaged (approximately 90\% reduction in the PL intensity and the PL signal broaden). This surface damage is typically due to ion implantation and surface amorphization during the Ga ions impingement. ${ }^{15}$ With GAFIB etching, the surface damage was minimized, with approximately $71 \%$ and $30 \%$ of the original $\mathrm{PL}$ intensity recovered for $\mathrm{XeF}_{2}$ and $\mathrm{I}_{2}$-assisted etching, respectively. In addition, the PL signals became narrower. The PL signal was recovered higher for $\mathrm{XeF}_{2}$ assisted etching because a lower number of $\mathrm{Ga}$ ions were implanted on the etched perovskite surface, as shown in the EDX spectra of Figure S2 (lower Ga signal for $\mathrm{XeF}_{2}$ compared to $\mathrm{I}_{2}$ and ions). Details of the EDX quantification are shown in Table S2. The PL signal recovered by GAFIB etching was comparable to other surface damage treatment for FIB patterning. For example, approximately $80 \%$ of the PL signal is recovered using thermal annealing ${ }^{25}$ for $\mathrm{GaN}$ and $>100 \% \mathrm{PL}$ signal is enhanced using plasma and acid treatments ${ }^{26}$ for diamond. In our case, the perovskite could be treated only 

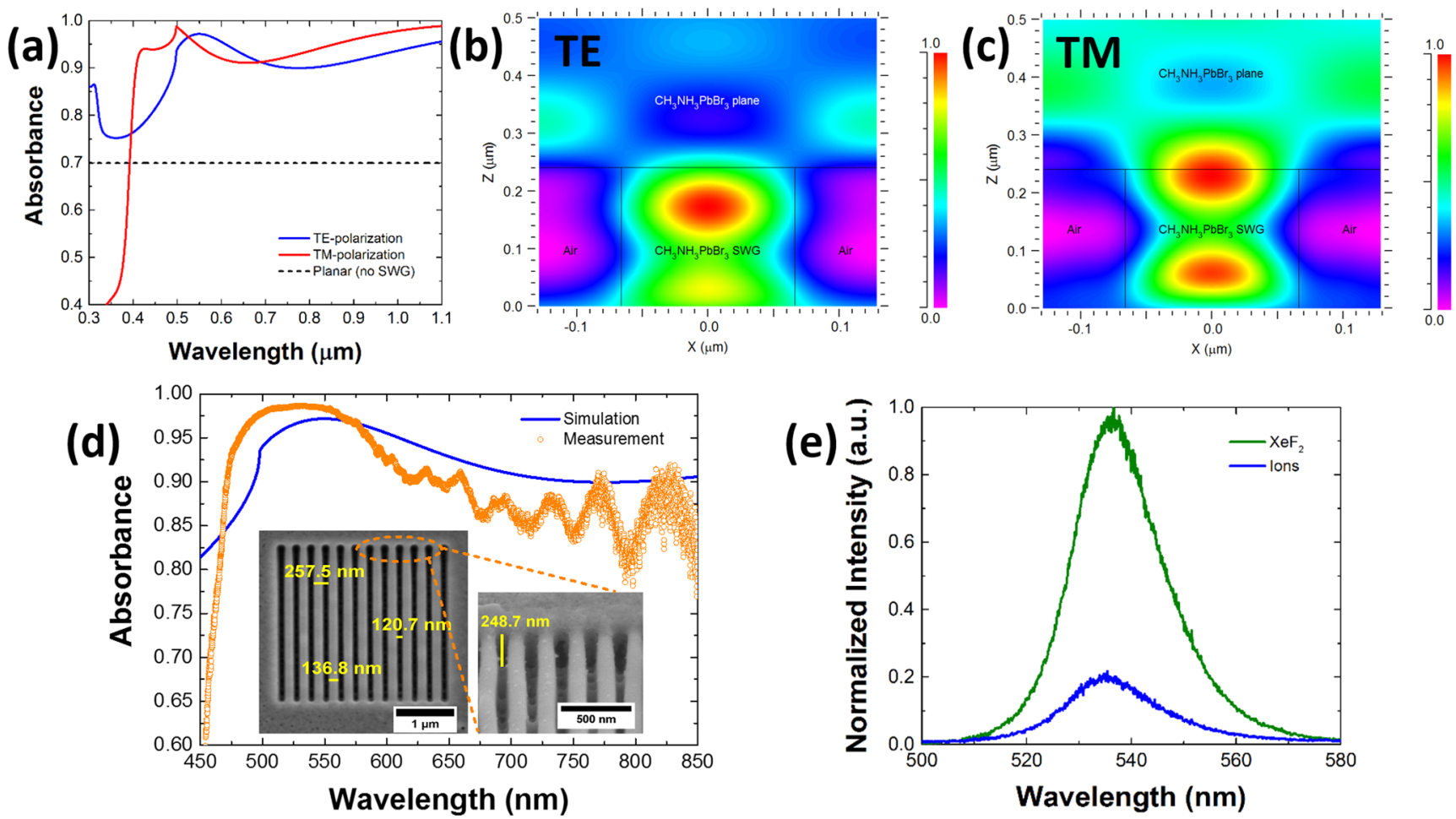

Figure 4. Design and fabrication of a perovskite SWG absorber showing (a) high absorption (>90\%) and a broadband spectrum for both TE- and TM-polarizations, (b) electric field distribution of TE polarization per period, (c) electric field distribution of TM polarization per period, (d) measured and simulated absorption spectra for TE polarization with SEM images inset (top-down view and $45^{\circ}$ tilt), and (e) PL spectra comparison for SWGs fabricated by GAFIB and FIB etching processes (the spectra are normalized to the GAFIB etching case for comparison).

using the GAFIB etching because thermal annealing and solvent degrade the perovskite material. Figure $3 \mathrm{~b}$ shows the Raman spectra for perovskite surfaces etched via FIB and GAFIB etching processes. Our spectra show good agreement with the reported spectra for this type of perovskite. ${ }^{27,28}$ There is no significant peak due to the nonexistence of Raman-active phonon modes in a crystal with cubic symmetry. ${ }^{27}$ We assumed that the broadening of the Raman signal (approximately 125$175 \mathrm{~cm}^{-1}$ ) occurred because of surface amorphization on the perovskite surface during the FIB and GAFIB etching processes, similar to the broadening observed in a ferroelectric film patterned with FIB. ${ }^{29}$ Similarly to the PL analysis, the Raman spectra exhibited signal recovery using the GAFIB etching, with the highest recovery obtained for $\mathrm{XeF}_{2}$ - followed by $\mathrm{I}_{2}$-assisted etching. The signal improvement for Raman after surface treatment (using thermal annealing) has also been observed for Si irradiated with FIB. ${ }^{30}$ For FIB application in photonic structures or devices, it is vital to treat the sample surface after patterning to minimize the effects of ion implantation and surface amorphization. Surface damage has been found to elevate free-carriers in a $\mathrm{Si}$ waveguide ${ }^{16}$ and create defect spots for optical absorption ${ }^{31}$ as well as changing the refractive index of the material. These problems will affect the optical signal quality for perovskites; therefore, the surface damage recovery using GAFIB etching is essential.

Figure 4 a shows the absorption spectrum for the perovskites SWG absorber calculated using the rigorous-coupled waveanalysis (RCWA) method. Utilizing SWG parameters of period, $257.8 \mathrm{~nm}$; grating thickness, $240.6 \mathrm{~nm}$; and fill-factor, 0.51 (schematic, design parameters, and modeling approach are described in Figure S4), the perovskite SWG absorber demonstrated high absorption (>90\%) and broadband spectrum (400-1100 nm) for both transverse electric (TE) and transverse magnetic (TM) polarizations. For comparison, we also computed the absorption spectrum for a planar perovskite (denoted as dashed line in Figure 4a). The spectrum showed approximately $70 \%$ light absorption; thus, enhancement of $>20 \%$ light absorption was achieved by integrating a SWG absorber on the perovskite material. Panels $b$ and $c$ of Figure 4 show a top-down view of the computed TE- and TMelectric field distributions, respectively, at the absorption peak for one period of perovskite SWG absorber. Intense light was localized between the grating and air interface, indicating that the incident light was trapped and absorbed through the SWG, with no light absorption in between (air media), for both polarizations. By designing the SWG periodicity smaller than the wavelength of the incoming light $(<300 \mathrm{~nm})$, only the zeroorder diffraction of light was propagated (absorbed) through each grating. Thus, the ability to pattern the perovskites at the submicron scale using the GAFIB etching is the key to realize this type of periodic photonic structure for device applications. On the basis of the calculated SWG parameters, we successfully patterned the SWG absorber on perovskites by GAFIB etching using $\mathrm{XeF}_{2}$. Figure $4 \mathrm{~d}$ shows the measured and simulated absorption spectra of the perovskite SWG absorber for TE polarized light. The measured and simulated spectra exhibit a similar trend and are in good agreement, particularly in the wavelength range of 500-650 $\mathrm{nm}$. Difference in the absorption intensity and multiple peaks existence at the longer wavelength $(>650 \mathrm{~nm})$ can be attributed to combination of nondispersion assumption in the simulation, scattering from the surface roughness of the fabricated perovskite SWG, and fabrication imperfection. Nevertheless, the patterned SWG absorber demonstrated high grating uniformity and periodicity across 
the entire patterning, as shown by SEM microscopy in the inset of Figure $4 \mathrm{~d}$. Utilizing the lower etching rate of $\mathrm{XeF}_{2}$-assisted etching, we achieved the patterning of a perovskite SWG absorber with nanoscale precision ( $\pm 4 \%$ fabrication tolerance of the design parameters). This lower etching rate was essential when controlling the grating thickness etching depth (inset of Figure $4 d$ ) because the perovskite sputtering rate is high $(>65$ times) compared to other materials, such as $\mathrm{Si}, \mathrm{GaAs}$, and PMMA. $^{11}$ More importantly, the GAFIB etching of $\mathrm{XeF}_{2}$ results in less surface damage, as mentioned previously. It is vital to maintain the optical properties of the perovskite material when patterning the SWG absorber to warrant a high solar cell PCE. Figure 4e shows the PL signal comparison for the fabricated perovskites SWG absorber using the GAFIB etching with $\mathrm{XeF}_{2}$ and the FIB etching. The optical property (PL signal) of the perovskite strongly deteriorated (approximately $80 \%$ ) if the SWG absorber was patterned solely using ions (nonchemically).

In summary, using $\mathrm{XeF}_{2}$ and $\mathrm{I}_{2}$ precursors, we demonstrated chemically assisted FIB direct etching of a perovskite. Compared to FIB etching using ions alone, this GAFIB etching process demonstrated advantages of etching enhancement and controllability while minimizing surface damage when utilized as surface treatment for perovskites patterning. These advantages are important for preserving the optical signal using surface treatment, considering that perovskites are easily etched and have limitations regarding annealing or solvent treatments. More importantly, using the GAFIB etching, we successfully accomplished direct submicron patterning of a perovskite SWG absorber with broadband absorption, high uniformity, and periodicity at nanoscale precision. This achievement is significant for perovskites because the material operating wavelength is in the visible spectrum. Our findings clear the path for controllable submicron direct patterning, nonlithographic, and nonthermal device processing for perovskite applications in photonic devices.

\section{ASSOCIATED CONTENT}

\section{S Supporting Information}

The Supporting Information is available free of charge on the ACS Publications website at DOI: 10.1021/acs.jpclett.5b02558.

Experimental methodology, FIB and GAFIB patterning parameters table, EDX quantitative table, SEM image of etch enhancement patterning, EDX spectra, SEM images of the perovskite surfaces etched by FIB and GAFIB etching processes, and schematic of the RCWA with modeling approach (PDF)

\section{AUTHOR INFORMATION}

\section{Corresponding Authors}

*E-mail: drsharizal@gmail.com.

*E-mail: boon.ooi@kaust.edu.sa.

\section{Present Address}

${ }^{\#}$ D.S.: Chemistry Department, National University of Singapore, 3 Science Drive, 117543 Singapore.

\section{Notes}

The authors declare no competing financial interest.

\section{ACKNOWLEDGMENTS}

This publication is based upon work supported by the King Abdullah University of Science and Technology (KAUST) baseline funding BAS/1/1614-01-01. We acknowledge the financial support from King Abdulaziz City for Science and Technology (KACST), Grant KACST TIC R2-FP-008.

\section{REFERENCES}

(1) Stranks, S. D.; Snaith, H. J. Metal-halide Perovskites for Photovoltaic and Light-Emitting Devices. Nat. Nanotechnol. 2015, 10, 391-402.

(2) Tan, Z.-K.; Moghaddam, R. S.; Lai, M. L.; Docampo, P.; Higler, R.; Deschler, F.; Price, M.; Sadhanala, A.; Pazos, L. M.; Credgington, D.; et al. Bright Light-Emitting Diodes based on Organometal Halide Perovskite. Nat. Nanotechnol. 2014, 9, 687-692.

(3) Deschler, F.; Price, M.; Pathak, S.; Klintberg, L. E.; Jarausch, D.D.; Higler, R.; Hüttner, S.; Leijtens, T.; Stranks, S. D.; Snaith, H. J.; et al. High Photoluminescence Efficiency and Optically Pumped Lasing in Solution-Processed Mixed Halide Perovskite Semiconductors. J. Phys. Chem. Lett. 2014, 5, 1421-1426.

(4) Dou, L.; Yang, Y.; You, J.; Hong, Z.; Chang, W.-H.; Li, G.; Yang, Y. Solution-Processed Hybrid Perovskite Photodetectors with High Detectivity. Nat. Commun. 2014, 5, 5404.

(5) Chin, X. Y.; Cortecchia, D.; Yin, J.; Bruno, A.; Soci, C. Lead Iodide Perovskite Light-Emitting Field-Effect Transistor. Nat. Commun. 2015, 6, 7383.

(6) Kaltenbrunner, M.; Adam, G.; Glowacki, E. D.; Drack, M.; Schwodiauer, R.; Leonat, L.; Apaydin, D. H.; Groiss, H.; Scharber, M. C.; White, M. S.; et al. Flexible High Power-per-Weight Perovskite Solar Cells with Chromium Oxide-Metal Contacts for Improved Stability in Air. Nat. Mater. 2015, 14, 1032-1039.

(7) Hoye, R. L. Z.; Chua, M. R.; Musselman, K. P.; Li, G.; Lai, M.-L.; Tan, Z.-K.; Greenham, N. C.; MacManus-Driscoll, J. L.; Friend, R. H.; Credgington, D. Enhanced Performance in Fluorene-Free Organometal Halide Perovskite Light-Emitting Diodes using Tunable, Low Electron Affinity Oxide Electron Injectors. Adv. Mater. 2015, 27, 1414-1419.

(8) Li, F.; Ma, C.; Wang, H.; Hu, W.; Yu, W.; Sheikh, A. D.; Wu, T. Ambipolar Solution-Processed Hybrid Perovskite Phototransistors. Nat. Commun. 2015, 6, 8238.

(9) Horantner, M. T.; Zhang, W.; Saliba, M.; Wojciechowski, K.; Snaith, H. J. Templated Microstructural Growth of Perovskite Thin Films via Colloidal Monolayer Lithography. Energy Environ. Sci. 2015, 8, 2041-2047.

(10) Wang, G.; Li, D.; Cheng, H.-C.; Li, Y.; Chen, C.-Y.; Yin, A.; Zhao, Z.; Lin, Z.; Wu, H.; He, Q.; et al. Wafer-Scale Growth of Large Arrays of Perovskite Microplate Crystals for Functional Electronics and Optoelectronics. Sci. Adv. 2015, 1, e1500613.

(11) Alias, M. S.; Dursun, I.; Shi, D.; Saidaminov, M. I.; Diallo, E. M.; Priante, D.; Ng, T. K.; Bakr, O. M.; Ooi, B. S. Focused-Ion Beam Patterning of Organolead Trihalide Perovskite for Subwavelength Grating Nanophotonic Applications. J. Vac. Sci. Technol. B 2015, 33, 051207.

(12) Ebm, C.; Platzgummer, E.; Loeschner, H.; Eder-Kapl, S.; Joechl, P.; Kuemmel, M.; Reitinger, R.; Hobler, G.; Koeck, A.; Hainberger, R.; et al. Ion Multibeam Nanopatterning for Photonic Applications: Experiments and Simulations, Including Study of Precursor Gas Induced Etching and Deposition. J. Vac. Sci. Technol. B 2009, 27, $2668-2673$.

(13) Loeschner, H.; Klein, C.; Platzgummer, E. Projection Charged Particle Nanolithography and Nanopatterning. Jpn. J. Appl. Phys. 2010, 49, 06GE01.

(14) Platzgummer, E. Maskless Lithography and Nanopatterning with Electron and Ion Multibeam Projection. Proc. SPIE 2010, 7637, 763703-763703-12.

(15) Roediger, P.; Wanzenboeck, H. D.; Waid, S.; Hochleitner, G.; Bertagnolli, E. Focused-Ion-Beam-Inflicted Surface Amorphization and Gallium Implantation-New Insights and Removal by FocusedElectron-Beam-Induced Etching. Nanotechnology 2011, 22, 235302.

(16) Tian, J.; Wei, Y.; Yazhao, L.; Luo, J.; Zhang, D.; Li, Z.; Min, Q. Optical Quality Improvement of Si Photonic Devices Fabricated by Focused-Ion-Beam Milling. J. Lightwave Technol. 2009, 27, 43064310 . 
(17) Callegari, V.; Sennhauser, U.; Jäckel, H. Analysis of the Propagation Losses of InP/InGaAsP Trench Waveguides Fabricated by Focused Ion Beam. Microelectron. Eng. 2010, 87, 2061-2064.

(18) Utke, I.; Hoffmann, P.; Melngailis, J. Gas-Assisted Focused Electron Beam and Ion Beam Processing and Fabrication. J. Vac. Sci. Technol. B 2008, 26, 1197-1276.

(19) Stark, T. J.; Shedd, G. M.; Vitarelli, J.; Griffis, D. P.; Russell, P. E. $\mathrm{H}_{2} \mathrm{O}$ Enhanced Focused Ion Beam Micromachining. J. Vac. Sci. Technol., B: Microelectron. Process. Phenom. 1995, 13, 2565-2569.

(20) Kim, C.-S.; Ahn, S.-H.; Jang, D.-Y. Review: Developments in Micro/Nanoscale Fabrication by Focused Ion Beams. Vacuum 2012, 86, 1014-1035.

(21) Wang, B.; Young Wong, K.; Xiao, X.; Chen, T. Elucidating the Reaction Pathways in the Synthesis of Organolead Trihalide Perovskite for High-Performance Solar Cells. Sci. Rep. 2015, 5, 10557.

(22) Sun, H. Y.; Lau, K. M.; Lau, K. C.; Chan, M. Y.; Fung, M. K.; Lee, C. S.; Lee, S. T. Fluorocarbon Film as Cathode Protective Coating in Organic Light-Emitting Devices. Appl. Phys. Lett. 2006, 88, 223503.

(23) Wheale, S. H.; Badyal, J. P. S. Xenon Difluoride Plasma Fluorination of Polymer Surfaces. Polymer 2011, 52, 5250-5254.

(24) Walker, P.; Tarn, W. H. CRC Handbook of Metal Etchants; CRC Press: Boca Raton, FL, 1991.

(25) Chyr, I.; Lee, B.; Chao, L. C.; Steckl, A. J. Damage Generation and Removal in the $\mathrm{Ga}^{+}$Focused Ion Beam Micromachining of $\mathrm{GaN}$ for Photonic Applications. J. Vac. Sci. Technol., B: Microelectron. Process. Phenom. 1999, 17, 3063-3067.

(26) Bayn, I.; Bolker, A.; Cytermann, C.; Meyler, B.; Richter, V.; Salzman, J.; Kalish, R. Diamond Processing by Focused Ion BeamSurface Damage and Recovery. Appl. Phys. Lett. 2011, 99, 183109.

(27) Matsuishi, K.; Ishihara, T.; Onari, S.; Chang, Y. H.; Park, C. H. Optical Properties and Structural Phase Transitions of Lead-Halide based Inorganic-Organic 3D and 2D Perovskite Semiconductors Under High Pressure. Phys. Status Solidi B 2004, 241, 3328-3333.

(28) Ledinský, M.; Löper, P.; Niesen, B.; Holovský, J.; Moon, S.-J.; Yum, J.-H.; De Wolf, S.; Fejfar, A.; Ballif, C. Raman Spectroscopy of Organic-Inorganic Halide Perovskites. J. Phys. Chem. Lett. 2015, 6, 401-406.

(29) Stanishevsky, A.; Nagaraj, B.; Melngailis, J.; Ramesh, R.; Khriachtchev, L.; McDaniel, E. Radiation Damage and its Recovery in Focused Ion Beam Fabricated Ferroelectric Capacitors. J. Appl. Phys. 2002, 92, 3275-3278.

(30) Xiao, Y. J.; Fang, F. Z.; Xu, Z. W.; Wu, W.; Shen, X. C. The Study of $\mathrm{Ga}^{+}$FIB Implanting Crystal Silicon and Subsequent Annealing. Nucl. Instrum. Methods Phys. Res., Sect. B 2013, 307, 253-256.

(31) Tanaka, Y.; Tymczenko, M.; Asano, T.; Noda, S. Fabrication of Two-Dimensional Photonic Crystal Slab Point-Defect Cavity Employing Local Three-Dimensional Structures. Jpn. J. Appl. Phys. 2006, 45, 6096. 